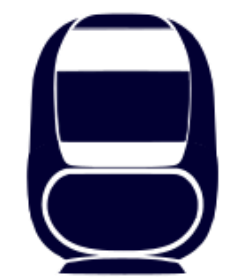

\title{
Demiryollarında Ön Germeli Traverslerin Farklı İşletme Yükleri Altında Mekanik Analizi
}

\author{
Yasin SARIKAVAK(D) \\ Ankara Yıldırım Beyazı Üniversitesi, Mühendislik ve Doğa Bilimleri Fakültesi, Makine \\ Mühendisliği Bölümü, Ankara, Türkiye \\ sarikavak@gmail.com
}

(Alinış/Received: 27.10.2020, Kabul/Accepted: 21.12.2020, Yaylmlama/Published: 31.01.2021)

Öz: Demiryollarında altyapı ve üstyapı en önemli bileșenler arasında yer almakta ve zorlu çevresel koşullara maruz kalmaktadır. Dinamik ve statik yükleri taşıyan, farklı iklim şartları altında çevresel koşullardan öncelikli olarak demiryolu altyapı ve üstyapı sistemleri etkilenmektedir. Bu çalışmada, demiryolu sistemleri için kritik bileşenler arasında yer alan ve Türkiye Cumhuriyeti Devlet Demiryolları (TCDD) bünyesinde ağırlıklı olarak kullanılan B70 ön germeli beton traverslerin farklı yükleme koşulları altında mekanik davranışları sonlu elemanlar yöntemi kullanılarak analiz edilmiştir. Sonlu elemanlar modeli zemin dolgu, alt balast ve balast katmanları; SKL14 tipi ray kıskacı, kauçuk malzemeden üretilmiş ray pedi, ray, travers ve demiryolu tekerinden oluşmaktadır. Analiz sonucu elde edilen deformasyon değerleri aynı yükler altında yapılmış deneysel çalışma sonuçlarıyla karşılaştırılmıştır. Geliş̧irilen sonlu elemanlar modeli sonucu elde edilen analiz sonuçlarının deneysel sonuçlarla uyumlu olduğu anlaşılmıştır.

Anahtar kelimeler: Travers, Demiryolu, Ön Germeli Travers, Sonlu Elemanlar Analizi, Deformasyon

\section{Mechanical analysis of prestressed sleepers under various operational loads in railways}

\begin{abstract}
In railways rail infrastructure and superstructure are the key components that works under harsh environmental conditions. Infrastructure and superstructure systems carries static and dynamic loads and are primarily imposed of various climate conditions. In this study, B70 prestressed concrete sleepers that are frequently used in Turkish State Railways are analysed by using finite element method for mechanical response under various loading conditions. Finite element model includes primary components of the systems such as, landfill, sub-ballast and ballast layers; SKL14 rail clip, rubber-based rail pad, rail, sleeper and vehicle wheel. Obtained deflection values with finite element results are compared and validated with the experimental work done at the same loading conditions. It is concluded that finite element results with developed model are compatible with the experimental results.
\end{abstract}

Keywords: Sleeper, Railway, Prestressed Sleeper, Finite Element Analysis, Deformation

\section{Giriş}

Demiryolu yolcu ve yük taşımacılı̆̆ açısından genel ulaştırma sistemleri içerisinde çevre dostu, verimli ve sürdürülebilir bir ulaştırma sistemidir. Demiryolu geçtiği bölgelerde sanayi, ticaret ve sosyal yaşamın gelişmesinde belirleyici olmuştur. Bu nedenle gelişmiş ve gelişmekte olan ülkeler demiryolu taşımacılığına önem vermekte ve ulaştırma modları içerisinde öncelikli olarak yatırım alanları içerisinde yer almaktadır. Ülkemizde yerleşik karayolu ağırlıklı ulaştırma sistemi 2000'li yıllardan itibaren değişerek demiryolu yatırımları öncelikli yatırım alanları arasında yerini almıştır. Mevcut demiryolu hatları yenilenmiş ve pek çok yeni yüksek hızlı tren hattı yatırımları planlanmış, projelendirilmiş ve işletmeye alınmıştır.

Türkiye'de konvansiyonel ve yüksek hızlı tren hatlarında balastlı üstyapı sistemleri mevcuttur. Bu sistem temel olarak üstyapıda ray, ray altı ped, ray bağlantı elemanları, balast tabakası, ön 
germeli beton traverslerden ve altyapıda ise alt balast tabakası ve zemin dolguları bileşenlerinden oluşmaktadır [1]. Dünyada farklı balastlı hatların haricinde, balastsız beton bloklu yollar (slab track) ve manyetik alan ile çalışan demiryolu hatları işletme altında günümüzde kullanılmaktadır. Bunun yanı sıra köprü, tünel vb. farklı yapılarda balastlı ve balastsız sistemlerin aynı hat üzerinde birleşim ve kesişim noktaları da yer alabilmektedir.

Dinamik ve statik yükleri taşıyan, farklı iklim şartları altında statik ve çevrimsel yük, gerilim, korozyon, aşınma gibi zorlu çevresel koşullara öncelikli olarak demiryolu altyap1 ve üstyap1 sistemleri maruz kalmaktadır. $\mathrm{Bu}$ nedenle her bir alt bileşen dikkatli seçilmeli ve ilgili standartlar, direktifler ve prosedürler takip edilerek doğru kalitede uygun malzemelerin seçilmesi sürdürülebilir ve güvenli demiryolu işletmeciliği açısından oldukça önemlidir. Altyapıda meydana gelebilecek potansiyel bir hasar telafisi güç olumsuzluklara neden olmaktadır. Bu nedenle özellikle yüksek hız ve yüksek aks yükleri altında altyapı ve bileşen malzemelerin incelenmesi önem arz etmektedir. Literatürde pek çok teorik ve deneysel çalışma demiryolu sistemlerinde uygun mühendislik yaklaşımlarını belirlemek için kullanılmaktadır. Teorik modellemede sonlu elemanlar yöntemi ile analiz pek çok demiryolu probleminin çözümünde kullanılmaktadır. Uygun altyapı dolgularının seçiminden [2], ray, travers ve bağlantı elemanlarının davranışına [3, 4], demiryolu araç dinamiğinden $[5,6]$, titreşim, gürültü ve yolcu konforuna [7] kadar pek çok konu teorik ve pratik olarak araştırılmış ve araştırılmaya devam etmektedir. Ön germeli beton traverslerdeki hasarın sonlu elemanlar yöntemi ve deneysel yöntem ile mekanik analizinin yapıldığı çalışmada [8] Brezilya (ABNT NBR 11709) ve AREMA standartlarına göre tasarlanmış traverslerin yük taşıma kapasiteleri incelenmiştir. Yapılan 18 adet deneysel çalışmada farklı bası yükleri traversin orta noktasına uygulanmış ve gerilim ve deformasyon değerleri incelenmiştir. Bir diğer çalışmada [9] ön germeli beton traverslerin kısa süreli ve yüksek büyüklükte darbe yükleri altındaki mekanik davranışları incelenmiştir. Benzer yükleme koşulları işletme şartlarında oldukça nadir görülmekle birlikte bu darbe yüklerinde traversin mekanik davranışı ve hasar analizi düşen ağırlık darbe testi ile incelenmiştir.

Bu çalışmada Türkiye Cumhuriyeti Devlet Demiryolları (TCDD) bünyesinde ağırlıklı olarak kullanılan B70 ön germe-ön çekmeli beton traverslerin farklı yükleme koşulları altında tepkisi sonlu elemanlar yöntemi kullanılarak analiz edilmiştir. Sonlu elemanlar modeli zemin dolgu, alt balast ve balast katmanları; Vossloh SKL14 tipi ray kıskacı, kauçuk malzemeden üretilmiş ray pedi, ray, travers ve demiryolu tekerinden oluşmaktadır. Literatürdeki çalışmalardan farklı olarak ülkemiz şartlarındaki işletme yükleri dikkate alınmıştır. Ayrıca modelde uygulanan yükler travers üzerindeki ray oturma yüzeyine rayın teması ile iletilmekte ve gerçek işletme şartlarını yüksek oranda temsil etmektedir. Analiz sonucu elde edilen deformasyon değerleri aynı yükler altında yapılmış deneysel çalışma sonuçlarıyla karşılaştııılmıştır.

\section{Metot}

Sonlu elemanlar ile analiz (SEA) yöntemi lineer davranış gösteren ve göstermeyen malzemelerin modellemesinde çoğunlukla kullanılan bir yöntemdir. Karmaşı mühendislik sistemlerinde malzeme ve/veya komple sistemlerin (pek çok alt bileşenden oluşan tam ölçekli sistemler) çeşitli yükler altında (işletme yükleri, artırılmış ve modifiye edilmiş yükler vb.) sınır koşulları dikkate alınarak mekanik, ssıl ve akışkan davranışları konusunda analiz yapma olanağı sunmaktadır.

Demiryolu traversi önemli bir demiryolu parçasıdır. Demiryolu araçlarının ray üzerinde hareketi sonucu oluşan yükler, ray tabanı ile traverslere iletilir ve bu yükler travers yardımıyla sırasıyla balast ve alt tabakaya iletilir ve yükün belirli ölçüde dağıtılıp sönümlenmesine olanak sağlar [10]. Türkiye Cumhuriyeti Devlet Demiryolları (TCDD) bünyesinde ağırlıklı olarak B70 ön germe-ön çekmeli beton traversler kullanılmaktadır. Ray oturma yüzeyi eğimli olup, balast çapı 
30-60 mm ve derinliği travers altından en az $30 \mathrm{~cm}$ olmalıdır. Traversler arası açılılık $60 \mathrm{~cm}$ olup aks yükü 22,5 ton/aks olarak tasarlanmıştır [11]. Demiryolu altyapı ve üstyap1 bileşenlerinden oluşan modelin üç boyutlu genel görünümü Şekil 1'de yer almaktadır.

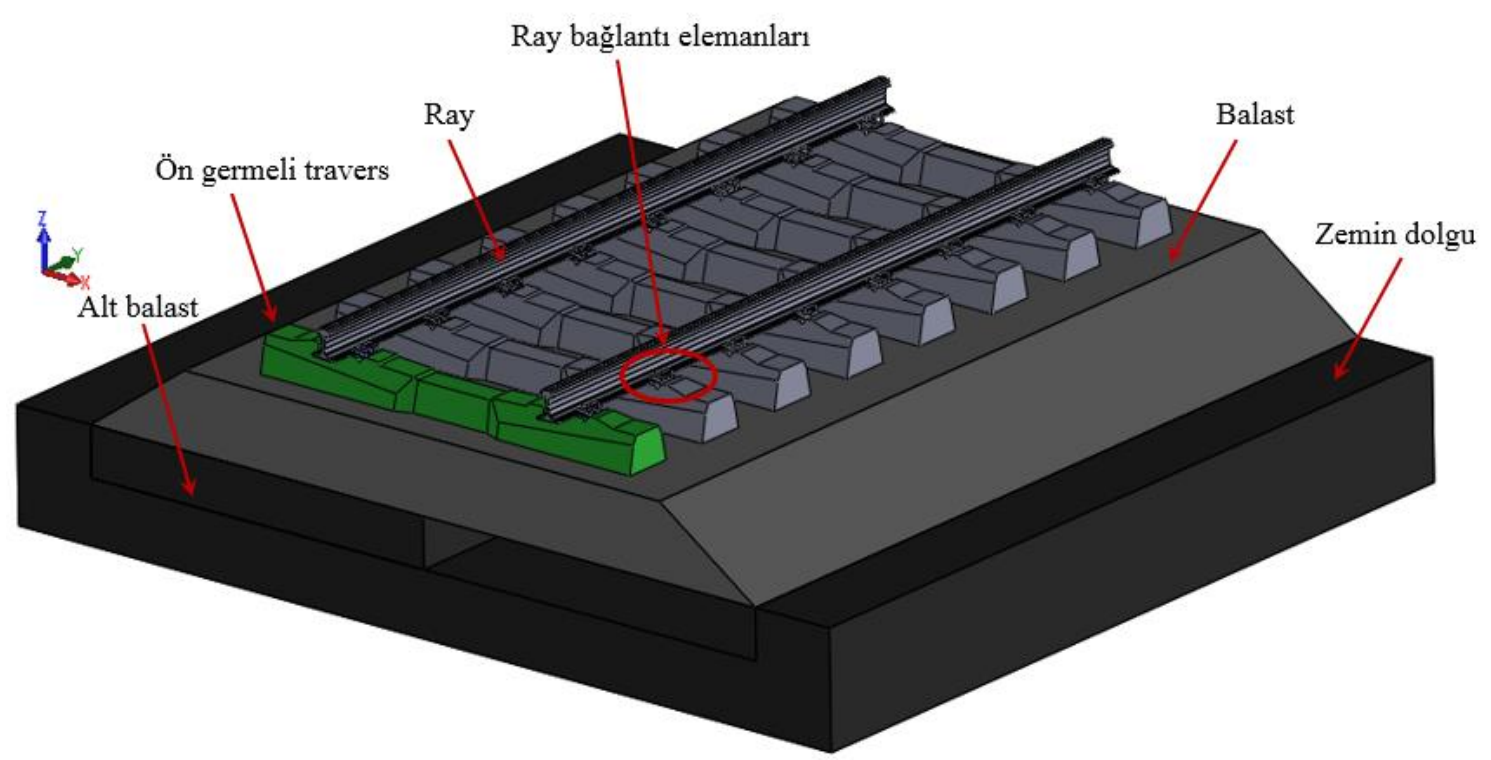

Şekil 1. Demiryolu altyapı ve üstyapı bileşenleri

Demiryolu altyap1 ve üstyapı bileşenlerine ait temel mekanik özellikler Tablo 1'de yer almaktadır. Bu değerler sonlu elemanlar analizinde kullanılan her bir malzemenin, malzeme özellikleri kısmında ayrı ayrı tanımlanmış ve bu değerler haricinde bu bölümde belirtilen diğer malzeme özellikleri modelde dikkate alınmıştır.

Tablo 1. Demiryolu altyapı ve üstyapı malzemelerinin mekanik özellikleri $[1,12]$

\begin{tabular}{cccc}
\hline Malzeme & Yoğunluk $\left(\mathrm{kg} / \mathrm{m}^{3}\right)$ & Young Modulü $(\mathrm{E})(\mathrm{GPa})$ & Poisson's Oranı $(v)(-)$ \\
\hline Ray & 7860 & 210 & 0,3 \\
Ray pedi & 1950 & 0,21 & 0,3 \\
Ön germeli travers & 1950 & 30 & 0,2 \\
Balast & 1730 & 0,13 & 0,1 \\
Alt balast & 2200 & 0,3 & 0,2 \\
Zemin dolgu & 2200 & 0,5 & 0,2 \\
\hline
\end{tabular}

Bu çalışmada beton ile ön germeli beton çelikleri arasında tam bağlanmanın olduğu kabul edilmiştir. Modelde kullanılan ray malzemesi en az 880 MPa çekme gerilimine ve $10 \%$ uzamaya sahiptir [13]. Kullanılan Vossloh SKL14 tipi ray kıskac1 200000 MPa Young modülüne (E), 0.3 Poisson's oranına ve $1300 \mathrm{MPa}$ akma gerilmesine sahiptir [14]. Modelde kullanılan araç tekerlek çapı 850 mm'dir.

Demiryolu altyap1 ve üstyap1 sisteminde boyuna düzlemde simetri olduğu için sonlu elemanlar analizi çalışmasında analiz sürelerini kısaltmak için yarım model kullanılmışıtır. Altyapı için altıyüzlü, üstyapı için dörtyüzlü ağdan oluşan sonlu elemanlar modeli 50107 düğüm ve 21996 elemandan oluşmaktadır. 


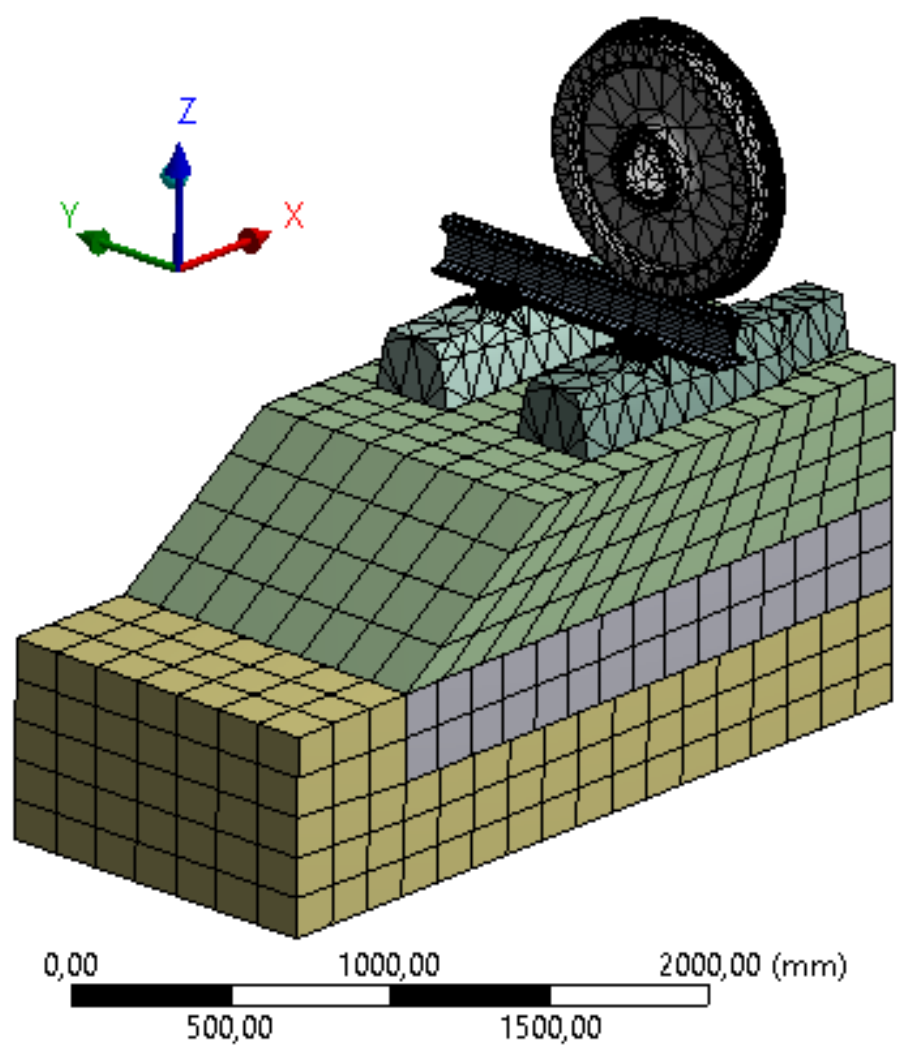

Şekil 2. Ağlara bölünmüş yarım modelden oluşan altyapı ve üstyapı sistemlerinin genel görünümü

Ayrıca, beton traverslerde ve demiryolu üstyapısında simetri olmasından ötürü yarım model kullanılmıştır. Kullanılan yarım modelde kontak noktalarında analiz hassasiyetini artırmak için ağ yoğunluğu artırılmış, kontak noktalarından uzak olan bölgelerde ise analiz süresini kısaltmak için daha seyrek ağlar kullanılmıştır. Ağlara bölünmüş yarım model Şekil 2'de yer almaktadır. Aks yükü tekerlek üzerinde yer alan aks boşluk yüzeyinde $-z$ ekseninde tanımlanmıştır.

\section{Bulgular}

TCDD envanterinde bulunan ve yüksek hızlı tren işletmeciliğinde kullanılan CAF 65000 model yüksek hızlı tren setleri 6 adet vagondan oluşmaktadır. Her vagonda çift akslı iki adet boji bulunmaktadır (Bo-Bo tip). Yolcularla birlikte en fazla ağırlığa sahip vagon (MIF 1B) $57510 \mathrm{~kg}$ ağırlığa sahiptir [15]. Vagonlarda bulunan boji tipi dikkate alındığında rayla ve üstyapıyla temas halinde olan ve aksla tekerleğe aktarılan en yüksek statik yük değeri 70,49 kN'dur. Diğer vagonlarda yer alan yükler, yolcular da dikkate alındığında en az $52050 \mathrm{~kg}$ vagon (TCF) statik yük değerine sahiptir [15]. Bu nedenle sonlu elemanlar analizi için $65 \mathrm{kN}$ yük ile başlanılmış ve sırasıyla, $70 \mathrm{kN}, 75 \mathrm{kN}, 100 \mathrm{kN}, 125 \mathrm{kN}, 150 \mathrm{kN}$ ve $175 \mathrm{kN}$ yükler altında B70 ön germe-ön çekmeli beton traversin yer değiştirme değerleri analiz edilmiştir. Şekil 3'te $65 \mathrm{kN}$ ve $70 \mathrm{kN}$ yükler altında üst ( $x-y$ düzlemi) ve yan ( $x-z$ düzlemi) yüzeyden bakıldığında traverste meydana gelen deformasyon yer almaktadır. Buna göre $65 \mathrm{kN}$ ve $70 \mathrm{kN}$ yükte en yüksek deformasyon sirasiyla $0,31 \mathrm{~mm}$ ve $0,33 \mathrm{~mm}$ olarak hesaplanmıştır.

Şekil 4'te $75 \mathrm{kN}$ ve $100 \mathrm{kN}$ yük altında sirasıyla en yüksek $0,36 \mathrm{~mm}$ ve $0,48 \mathrm{~mm}$ deformasyon gözlenmiştir. Analiz yükleri artırıldığında $125 \mathrm{kN}$ ve $150 \mathrm{kN}$ yükte sırasıyla $0,60 \mathrm{~mm}$ ve 0,72 mm deformasyon (Şekil 5) ve $175 \mathrm{kN}$ yükte $0,84 \mathrm{~mm}$ deformasyon (Şekil 6) değerleri elde edilmiştir. 

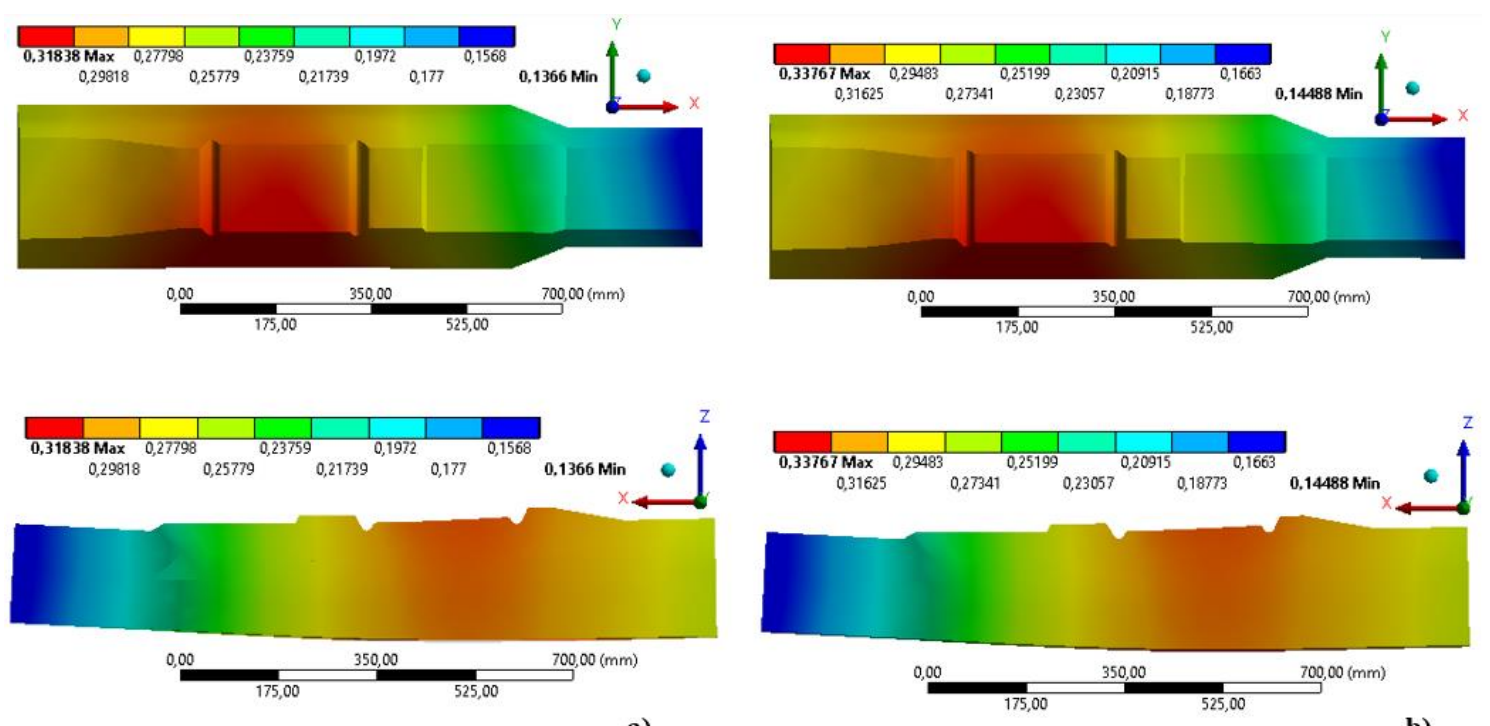

a)

b)

Şekil 3. B70 ön germe-ön çekmeli travers üst ve yan görünümü a) $65 \mathrm{kN}$ yük altında toplam deformasyon b) $70 \mathrm{kN}$ yük altında toplam deformasyon
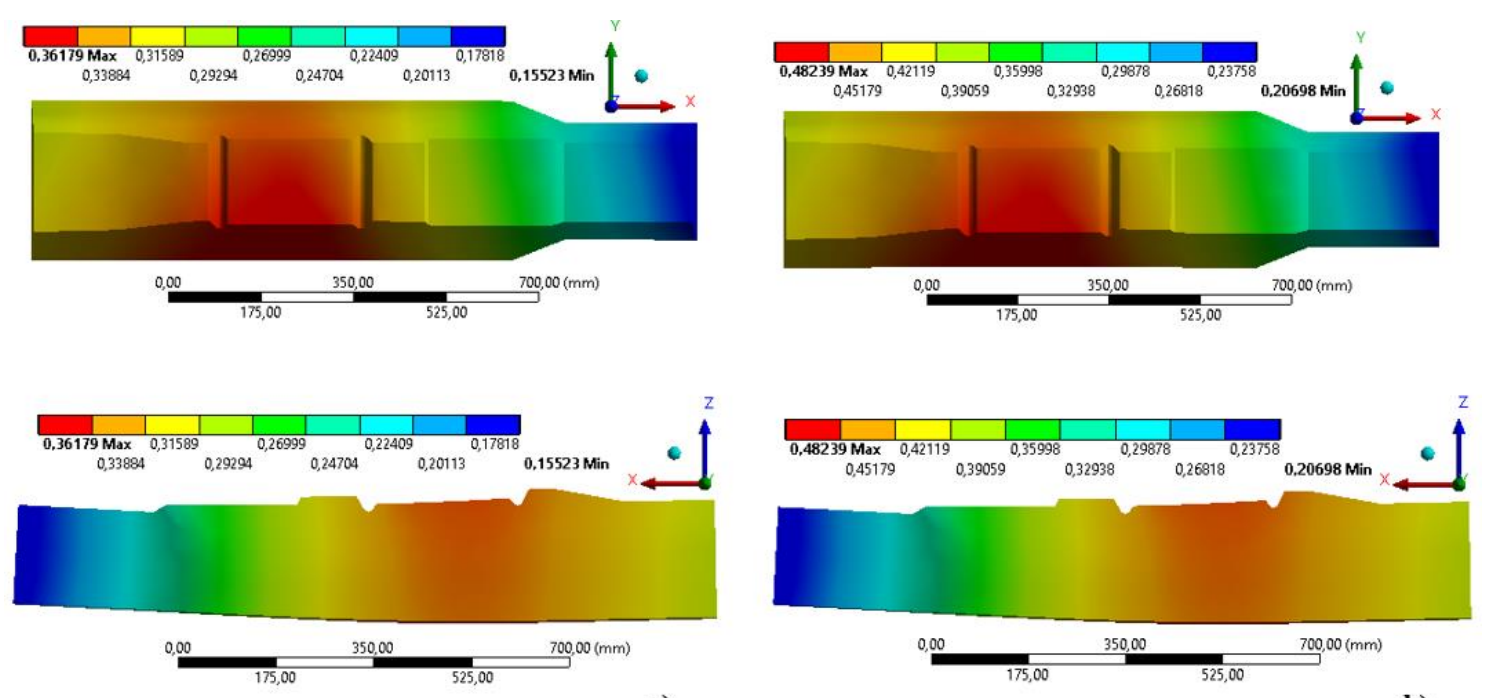

a)

Şekil 4. B70 ön germe-ön çekmeli travers üst ve yan görünümü a) $75 \mathrm{kN}$ yük altında toplam deformasyon b) $100 \mathrm{kN}$ yük altında toplam deformasyon

Demiryolu aracından kaynaklanan yük aks ve tekerlek aracıllğııla raya iletilir. Ray ve bağlantı elemanları bu yükün bir kısmını sönümler ve yük ray tabanından kauçuk bir malzeme olan ve ray-travers arasına yerleştirilen ray pedine ve oradan da traverslere iletilir. Şekil 3-6'da görüldüğü üzere yükün artmasıyla traverste meydana gelen yük artmaktadır. Beklenildiği gibi en fazla deformasyon rayın ve ray pedinin oturduğu eğimli yüzeyde meydana gelmektedir. Deformasyon kademeli olarak ray oturma yüzeyinden uzaklaştıkça azalmakta ve en düşük değer traversin orta noktasında oluşmaktadır.

Gustavson [16] çalışmasında, ortasından dikey eksende kesilmiş 6 adet traverse deneysel yük uygulayarak çeşitli noktalara yerleştirilmiş yük hücresi, gerinim ölçer ve yer değiştirme sensörleri vasıtasıyla gerçek şartlarda veriler toplamıştır. Buna göre $65 \mathrm{kN}$ yükte $0,21 \mathrm{~mm} ; 100$ $\mathrm{kN}$ yükte $0,43 \mathrm{~mm} ; 150 \mathrm{kN}$ yükte $0,72 \mathrm{~mm}$ deformasyon olduğu görülmüsstür. Sonlu elemanlar analizi sonucu elde edilen sonuçlar dikkate alındığında farklı yükleme şartları altında deneysel 
sonuçlara oldukça yakın sonuçların elde edildiği görülmektedir. Deneysel çalışmalarda ortalama $135 \mathrm{kN}$ ve $150 \mathrm{kN}$ yüklerde görsel muayene ile çatlak oluşumu gözlenmiş ve bu değerlerin mukavemet açısından kritik yüklemeler olduğu sonucuna varılmıştır.
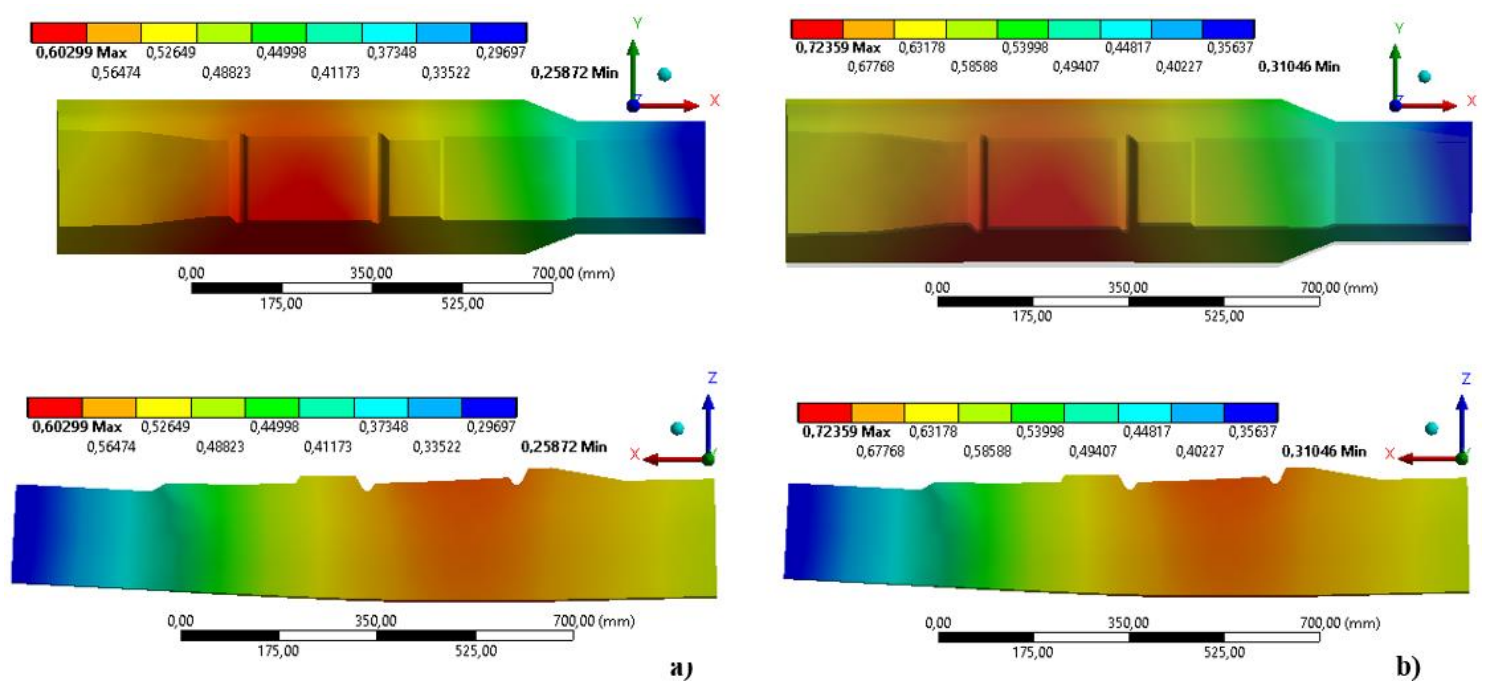

Şekil 5. B70 ön germe-ön çekmeli travers üst ve yan görünümü a) $125 \mathrm{kN}$ yük altında toplam deformasyon b) $150 \mathrm{kN}$ yük altında toplam deformasyon
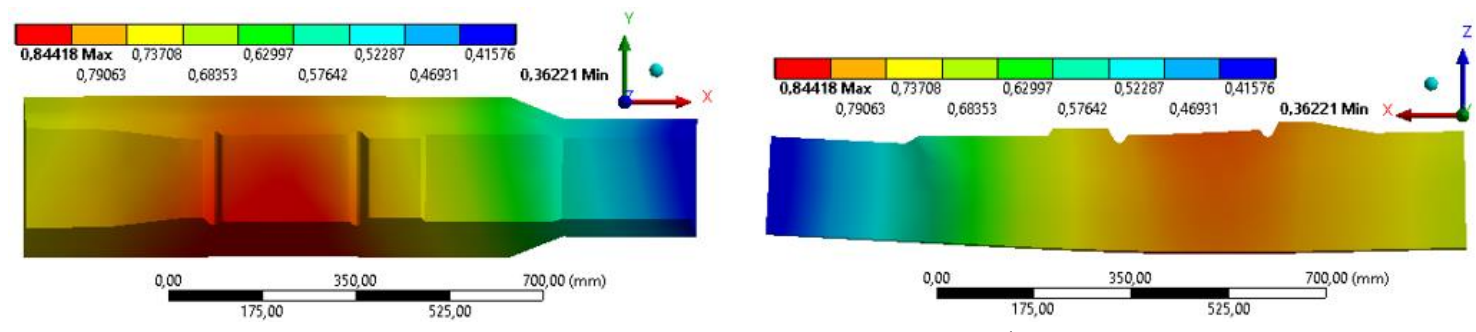

Şekil 6. B70 ön germe-ön çekmeli travers üst ve yan görünümü (175 kN yük altında toplam deformasyon)

\section{Sonuç}

Bu çalışmada sonlu elemanlar yöntemi ile analiz yapılarak B70 ön germe-ön çekmeli beton traverslerin gerçek işletme yükü ve artırılmış yükler altındaki statik davranışı incelenmiştir. Lineer olmayan sonlu elemanlar modeli balastlı demiryolu sistemini temsil edecek zemin dolgu, alt balast ve balast katmanlar1, ray kıskac1, ray pedi, ray, travers ve demiryolu tekerinden oluşmaktadır. Buna göre her yükleme durumu için en yükssek deformasyon değerlerinin ray oturma yüzeyinde gerçekleştiği, kademeli olarak travers merkezine ve köşesine doğru azaldığ 1 anlaşılmıştır. Travers kalınlığı boyunca da (travers tabanı) deformasyon değerinin azaldığ 1 anlaşılmıştır. Farklı yükler altında elde edilen değerlerin deneysel sonuçlarla uyumlu olduğu görülmüş ve geliştirilen lineer olmayan statik modelin B70 ön germeli traversler için faydalı ve gerçekçi sonuçlar verdiği görülmüştür. Bundan sonraki çalışmalarda farklı travers modellerinin performans ve hasar analizleri için bu çalışmada önerilen model kullanılarak simülasyon çalışmaları yapılabilir.

\section{Kaynakça}

[1] M. Shahraki, C. Warnakulasooriya, and K. J. Witt, "Numerical study of transition zone between ballasted and ballastless railway track," Transp. Geotech., vol. 3, pp. 58-67, 2015, doi: 10.1016/j.trgeo.2015.05.001.

[2] K. Oğul, U. Mutman, and E. Poşluk, "Yüksek hızlı demiryollarında kullanılan yaklaşım dolgu 
modellerinin sayısal analiz ile değerlendirilmesi," Demiryolu Mühendisliği, no. 10, pp. 46-53, 2019.

[3] Q. Wu, et al., "Railway track longitudinal force model," Veh. Syst. Dyn., vol. 0, no. 0, pp. 1-16, 2019, doi: 10.1080/00423114.2019.1673445.

[4] A. Strauss et al., "Nonlinear finite element analysis of continuous welded rail-bridge interaction: monitoring-based calibration," J. Civ. Eng. Manag., vol. 24, no. 4, pp. 344-354, 2018, doi: 10.3846/jcem.2018.3050.

[5] E. Di Gialleonardo, F. Braghin, and S. Bruni, "The influence of track modelling options on the simulation of rail vehicle dynamics," J. Sound Vib., vol. 331, no. 19, pp. 4246-4258, 2012, doi: 10.1016/j.jsv.2012.04.024.

[6] L. Auersch, "Dynamic axle loads on tracks with and without ballast mats: numerical results of threedimensional vehicle-track-soil models," Proc. Inst. Mech. Eng. Part F J. Rail Rapid Transit, vol. 220, no. 2, pp. 169-183, 2006, doi: 10.1243/09544097F00105.

[7] D. P. Connolly et al., "Benchmarking railway vibrations - track, vehicle, ground and building effects," Constr. Build. Mater., vol. 92, pp. 64-81, 2015, doi: 10.1016/j.conbuildmat.2014.07.042.

[8] R. Silva et al., "Experimental and numerical analyses of the failure of prestressed concrete railway sleepers," Materials (Basel)., vol. 13, no. 7, 2020, doi: 10.3390/ma13071704.

[9] S. Kaewunruen and A. M. Remennikov, "Impact capacity of railway prestressed concrete sleepers," Eng. Fail. Anal., vol. 16, no. 5, pp. 1520-1532, 2009, doi: 10.1016/j.engfailanal.2008.09.026.

[10] S. Kaewunruen and A. M. Remennikov, "Nonlinear finite element modeling of railway prestressed concrete sleeper," Real Struct. Bridg. Tall Build. - Proc. 10th East Asia-Pacific Conf. Struct. Eng. Constr. EASEC 2010, vol. 4, pp. 323-328, 2006.

[11] TCDD, "Ön germe-ön çekmeli beton travers teknik şartnamesi," Ankara, 2011.

[12] A. Paixão et al., "Numerical simulations to improve the use of under sleeper pads at transition zones to railway bridges," Eng. Struct., vol. 164, no. September 2017, pp. 169-182, 2018, doi: 10.1016/j.engstruct.2018.03.005.

[13] EN 13674-1, "Railway applications - Track - Rail - Part 1: Vignole railway rails 46 kg/m and above applications," 2013.

[14] S. Mohammadzadeh, S. Ahadi, and H. Keshavarzian, "Assessment of fracture reliability analysis of crack growth in spring clip type Vossloh SKL14," Proc. Inst. Mech. Eng. Part O J. Risk Reliab., vol. 228, no. 5, pp. 460-468, 2014, doi: 10.1177/1748006X14527926.

[15] TCDD, CAF, and Geminys, "Operators Manual," 2008.

[16] R. Gustavson, "Static and dynamic finite element analyses of concrete sleepers," pp. 49-66, 2000.

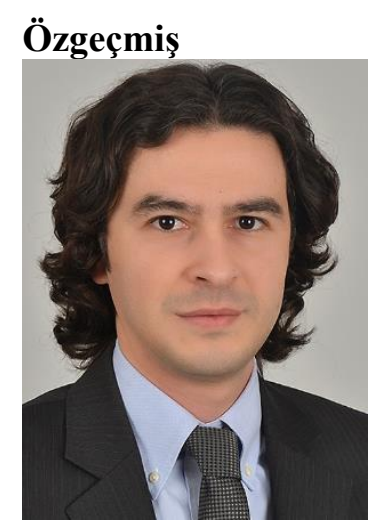

Beyanlar:

\section{Yasin SARIKAVAK}

Makine Yüksek Mühendisi, Dr. Lisans eğitimini 2006 yılında Gazi Üniversitesi, Mühendislik Mimarlık Fakültesi, Makine Mühendisliği Bölümü'nde tamamlamıştır. Aynı yıl TCDD, Ankara Demiryolu Fabrikas1, Motor Grup Müdürlügü̈'nde mühendis olarak göreve başlamıştır. 2009 yılında Yüksek Hızlı Tren Bakım Onarım Müdürlüğü'nde görev yapmıştır. 2011 yılında kurulan Demiryolu Araştırma ve Teknoloji Merkezi (DATEM)'nin kurucu mühendisleri arasında yer almıştır. Halen Ankara Yıldırım Beyazıt Üniversitesi, Mühendislik ve Doğa Bilimleri Fakültesi, Makine Mühendisliği Bölümü'nde öğretim üyesi olarak görev yapmaktadır.

E-Posta: sarikavak@gmail.com; ysarikavak@ybu.edu.tr

Bu makalede bilimsel araştırma ve yayın etiğine uyulmuştur. 